\title{
PROMOTION OF ENGINEERING SKILLS USING ICT IN STUDY PROCESS
}

\author{
Anda Zeidmane \\ Latvia University of Life Sciences and Technologies, Latvia \\ anda.zeidmane@1lu.lv
}

\begin{abstract}
Engineering programmes firstly should become more attractive to attract a sufficient number of students, and secondly programmes should develop practical skills demanded by the labour market. Without an adequate level of ICT competence, career development of individuals is limited, so it is essential to integrate ICT into the engineering study process. Three types of ICT skills (General-purpose Software, Engineering Software and Information Skills) based on four categories of ICT tools (Informative, Constructive, Communicative or Situative) are the core of engineering education. The aim of this study is to investigate how the inclusion of ICT in the study process promotes the development of engineering skills and students' readiness to use ICT in the study process at the Latvia University of Life Sciences and Technologies (LLU). The sample size of the study consisted of 301 students (first and second year) from the engineering specialities of the LLU. Objectives of the study are firstly, to identify how mathematics studies and the inclusion of ICT in them can promote the development of engineering skills, secondly, through a survey of students, to identify the purposes and frequency of academic use of ICT and use of ICT in mathematics (one of the engineering subjects) study process. For studying Mathematics in the LLU students use ICT firstly, independently studying e-materials (both informative and interactive), secondly, acquiring MATLAB program for problem solving and thirdly, in addition, the students can use Internet resources to find information, use mathematical programs as well as communicate online in chats. Inclusion of ICT in the Mathematics studies develops the skills necessary for engineers such as communication, technical skills and teamwork. Increasing the impact of ICT in the study process, not only many students will have to change their learning style, but also the teaching staff will have to change the study process.
\end{abstract}

Keywords: use of ICT, learning process, mathematics study.

\section{Introduction}

According to the SEFI (European Society for Engineering Education) Engineering Education Research work group studies, the important issues for the future of engineering education are the need for new competences and the ability to deal with new types of interdisciplinary and complex knowledge [1].

There have been many studies on key engineering skills. According to employers, the most important skills of 10 for modern engineers are the following [2].

- Communication - is important in brainstorming, project meetings, product development and most importantly in problem solving (using mobile phones, Skype, online meetings etc. ICT tools).

- Interpersonal skills - it can be practiced by cooperating in the workplace, developing a positive attitude towards themselves, others and circumstances;

- Problem solving - it is needed to identify, evaluate, and analyze complex problems.

- Technical skills - that includes being up to date with modern technology, industry trends and development.

- Motivation - by showing enthusiasm and commitment that demonstrate interest in the company and their vision.

- Industry knowledge - it means being knowledgeable in Science, Technology, Engineering, and Mathematics.

- Analytical mind - it means both analyzing the problem and experimenting and testing it.

- Attention to detail - for being able to pay attention to every detail to make sure that nothing important gets forgotten

- Teamwork abilities - to be comfortable working with other people, because with serious projects, engineers work with a team.

- Leadership and management skills - to be able to assess and utilize members' abilities to form an effective team for project implementation.

There are two main aspects to the development of engineering education. First, engineering programs need to become more attractive to attract a sufficient number of students, and secondly programmes should develop practical skills demanded by the labour market [3]. Without an adequate 
level of ICT competence, career development of individuals is limited, so it is essential to integrate ICT into the engineering study process.

The pedagogical methodology of "Learning by Doing" requires integration of ICT-based learning activities to help students acquire knowledge and skills in the "doing "of engineering projects.

For introducing the above mentioned in the study process, students need ICT literacy. What exactly is ICT literacy? As defined by the International ICT Literacy Panel, "ICT literacy is using digital technology, communications tools, and/or networks to access, manage, integrate, evaluate, and create information in order to function in a knowledge society" [4].

Engineering education emphasizes three types of ICT skills (General- Purpose Software, Engineering Software, Information skills) and four categories of ICT tools that can be used by engineering education students in four ways as informative, constructive, communicative or situative, "Fig. 1" [5].

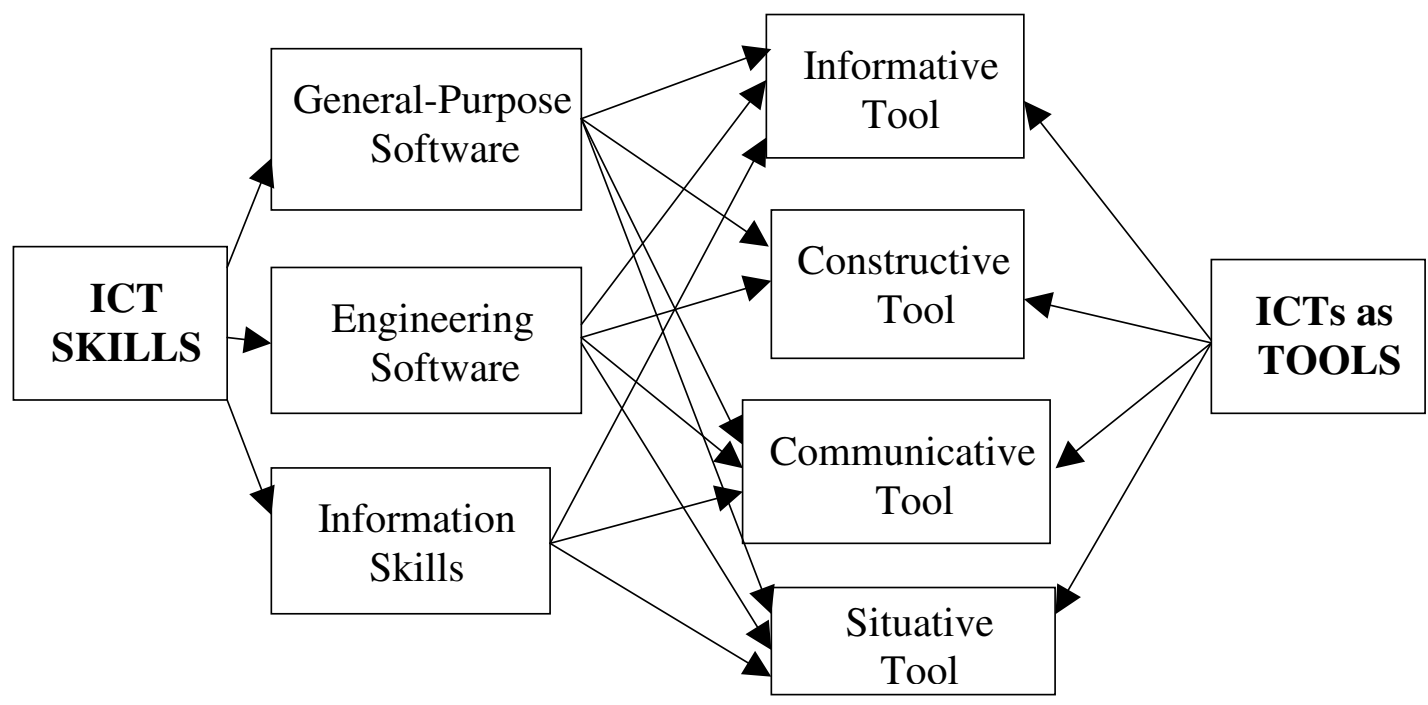

Fig. 1. Thematic map of students' ICT skills conception

Skills in using information tools mean that students will be able to use various information provided on the Internet, such as text, graphics, sound, video, multimedia encyclopaedias etc. Constructive tools can be used to manipulate information, visualizing awareness and generate new knowledge. More or less students know communicative tools (mobile phones, WhatsApp, Skype, online meetings etc.), but the question is how much they use them and for what purposes. Situational tools can create 3D images on the display to give the user a feeling of being in a virtual environment.[6]

However, the inclusion of ICT in the study process does not yet guarantee the successful development of engineering competences. A lot depends on the students' study habits, use of ICT in everyday life and learning process. This raises many questions that are important for students, for example:

- how much time students spend using computers and smartphones,

- what are the purposes of using the Internet [7],

- whether there is a correlation between academic use of ICT, non-academic and social use of ICT, ICT addiction and students' performance [8],

- whether students know how to use and actually use educational software to improve the educational process.

The aim of this study is to investigate how the inclusion of ICT in the study process promotes the development of engineering skills and students' readiness to use ICT in the study process at the Latvia University of Life Sciences and Technologies (LLU).

Objectives of the study are: 
1) to identify how mathematics studies and the inclusion of ICT in them can promote the development of engineering skills;

3 ) to determine the purposes and frequency of use of ICT in mathematics (one of the engineering subjects) study process;

4) to explore the students' attitude towards self-assessment tests as support for the study process, and how tests' results relate with student performance in mathematics.

\section{Materials and methods}

Mathematics is an integral part of engineering education, therefore, it is essential to be aware of the role of mathematics in modern engineering education and the labour market [9]. The substance of mathematics for universities is determined by the SEFI (European Society for Engineering Education) [10]:

- Mathematics as a subject sees mathematics as part of the degree programme, to be studied via various teaching and learning techniques.

- Mathematics as the basis of other subjects.

- Mathematics as a tool for analysing problems, coexisting with other fields of knowledge and supporting research and development of this knowledge.

Teaching content in mathematics studies provides the engineering skills employers mentioned such as problem solving, industry knowledge, analytical mind.

A study was conducted in 2018 and 2019 by the University of Life Sciences and Technology (LLU) to determine students' habits of using ICT in everyday life and in the study process. Primary data were obtained from respondents using a close ended questionnaire. As sample size consisted of 301 first and second year students (the principle of an occasional selection) from the Faculty of Engineering (92 students), the Faculty of Information Technology (122 students), the Faculty of Food Technology (29 students from Food and Nutrition Science specialties) and the Faculty of Forestry (58 students from Forest Engineering and Wood Processing specialties).

The questionnaire was designed with closed questions, including various answers. The questionnaire was divided into two main areas. The first part of the questionnaire focused on how much time students spend using ICT for academic purposes, social networking and entertainment, and their specific interest in using ICT. The second part of the questionnaire included questions to determine students' learning habits. The survey included questions about how often students: 1) use contact lessons and self-built lecture conspectus; 2) communicate in consultation or learning with friends; 3) use e-learning tools (informative and interactive); 4) internet resources (looking for specific information or using other math programs besides MatLab included in the course).

The application software Microsoft Excel was used in order to process the quantitative research data, to perform statistical analysis and to visualize results. Software package IBM SPSS was used for correlation analysis with the Spearman' coefficient.

\section{Results and discussion}

In order to identify how mathematics studies and the inclusion of ICT in them can promote the development of engineering skills, the mathematics study process at LLU was analyzed.Organization of mathematics study process (including ICT) could develop communication (contact and online), technical skills and teamwork abilities. Mathematics study process in LLU provides not only contact lessons (lectures and practical work), but also individual work. In mathematics studies, the emphasis is on solving specific problems, therefore questions of a theoretical nature (evidence, understanding of formulas, possibilities of application of methods, etc.) are tested in the e-environment, which gives additional points in the final assessment. Students test the solutions to their individual problems with the with MatLab software or Excel in laboratory works. In addition, students are offered small group counselling that could develop skills useful for engineers such as communication and teamwork. For studying Mathematics in the LLU students use ICT firstly, independently studying e-materials (both informative and interactive), secondly acquiring MATLAB program for problem solving and thirdly, 
in addition, the students can use Internet resources to find information, use mathematical programs as well as communicate online in chats.

Using ICT technologies is an integral part of student life. The question is what the purposes of using the internet are and how students' habits of using ICT influence their study process.

In order to find out how much time LLU students from engineering faculties use the Internet for academic purposes and for non-academic ones, which includes social communication and for entertainment purposes, students of LLU engineering faculties were surveyed "Table 1". The table uses data from a survey conducted in 2018 [11] and in 2019.

Time distribution of using the Internet of students of the

Table 1

Latvia University of Life Sciences and Technologies (LLU)

\begin{tabular}{|c|c|c|c|c|c|c|c|}
\hline $\begin{array}{c}\text { Time } \\
\text { distribution of } \\
\text { using the } \\
\text { Internet }\end{array}$ & $\begin{array}{c}\text { Students of the } \\
\text { Faculty of } \\
\text { Engineering } \\
(\mathbf{E F})\end{array}$ & $\begin{array}{c}\text { Students of the } \\
\text { Faculty of } \\
\text { Information } \\
\text { Technology (ITF) }\end{array}$ & \multicolumn{2}{|c|}{$\begin{array}{c}\text { Students of the } \\
\text { Faculty of Food } \\
\text { Technology } \\
\text { (FTF) }\end{array}$} & $\begin{array}{c}\text { Students } \\
\text { of the } \\
\text { Forest } \\
\text { Faculty } \\
\text { (FF) }\end{array}$ \\
\cline { 2 - 8 } & $\mathbf{2 0 1 8}$ & $\mathbf{2 0 1 9}$ & $\mathbf{2 0 1 8}$ & $\mathbf{2 0 1 9}$ & $\mathbf{2 0 1 8}$ & $\mathbf{2 0 1 9}$ & $\mathbf{2 0 1 9}$ \\
\hline $\begin{array}{c}\text { Academic use of } \\
\text { ICT }\end{array}$ & $31.4 \%$ & $30.3 \%$ & $38.4 \%$ & $39.8 \%$ & $32.5 \%$ & $36.4 \%$ & $35.6 \%$ \\
\hline $\begin{array}{c}\text { Communicating } \\
\text { in Social } \\
\text { Networks }\end{array}$ & $16.3 \%$ & $17.8 \%$ & $14.5 \%$ & $14.9 \%$ & $30.8 \%$ & $27.5 \%$ & $23.3 \%$ \\
\hline Entertainment & $52.3 \%$ & $51.9 \%$ & $47.1 \%$ & $45.3 \%$ & $36.7 \%$ & $36.1 \%$ & $41.1 \%$ \\
\hline
\end{tabular}

The results of the study show that on average $35 \%$ of the time spent in ICT is devoted to academic purposes. As for the non-academic purposes, the results of the various faculties are different. For example, at the Faculty of Food Technology (FTF) for social networking, the student spent $30.8 \%$ of the time in 2018, the student of the year $2019-27.5 \%$ (mode = median = "partly"), while the student of the Faculty of Information Technology (ITF) only in $2018-14.5 \%$, in $2019-14.9 \%$ ( mode $=$ median $=$ "partly"). This could be explained by the fact that in the faculty of IT majority are males and in the faculty of FTF majority are females. At the same time, students at the Forest Faculty (FF) with a higher proportion of females than ITF spend $23.3 \%$ (mode = median = "partly") of their time on social networks. Comparing the results over the years it can be concluded that in 2019 the time spent by students for entertainment has slightly decreased in all faculties. This could indicate that students are playing less computer games and more looking for entertainment in real life.

A second part of questionnaire was developed to investigate students' learning habits and to find out the purposes and frequency of using ICT in mathematics. For comparison, research data is provided at the Faculty of Food Technology (FTF) and Forestry (FF) in 2019. It should be noted that the results in mathematics for students of the FTF were significantly better than those of the FF.

Students from FTF prefer contact learning (regularly $-64.3 \%$, often $-21.4 \%$ ), and learning from their conspects (regularly $-57.1 \%$, often $-42.9 \%)$, (mode = median = "partly") "Fig.2". In contrast, students from FF prefer less to learn in contact classes (regularly $-32.5 \%$, often $-35.0 \%$ ) and from their conspectus (regularly $-32.5 \%$, often $-42.5 \%)$, (mode $=$ median $=$ "partly") "Fig. 3 ". This could be explained by the fact that the FF students had a weaker basic knowledge in mathematics and that it is more difficult for them to perceive the content of lecture and create their own synopses. Recording of lectures in the e-environment, using BigBlueButton is currently practiced, so that students have the opportunity to view the lecture several times at their own pace. Students are positive about this opportunity. Then the question arises as to whether students need to attend contact lectures. The function of lectures could be consultative rather than informative. However, this can only happen if the students have listened to the lecture in the e-environment before.

On the other hand, students from FF prefers communication - learning with friends: regularly $64.3 \%$, often- $21.4 \%$ "Fig. 3 ", where a students from FTF only regularly $-32.5 \%$, often $-42.5 \%$, ( mode $=$ median $=$ "partly ")" Fig. 2 ". This shows that it is easier for students to ask each other than to 
look for answers themselves. Of course, it depends on students' learning styles, but as ICT increases in the study process, these styles may change.

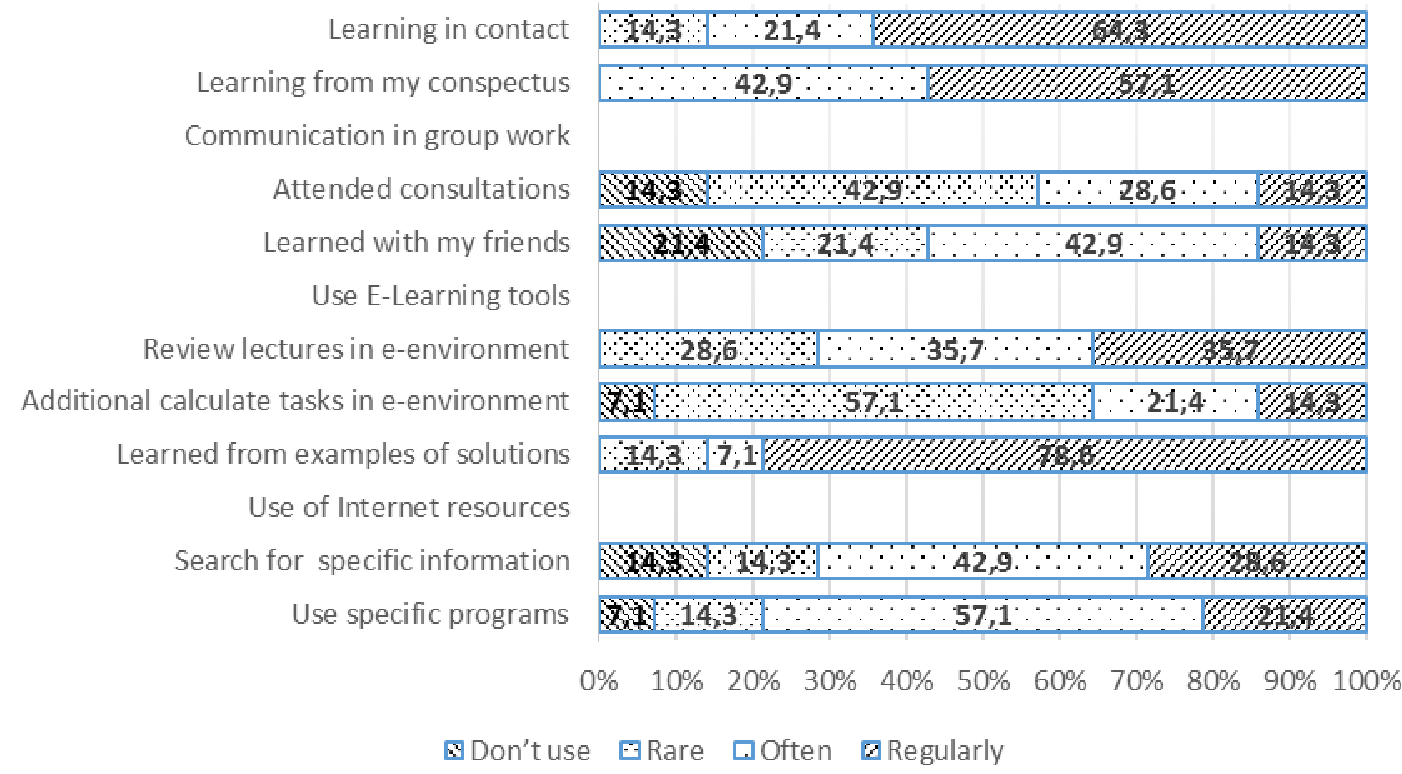

Fig. 2. Learning habits and frequency of mathematics students of the Faculty of Food Technology of LLU

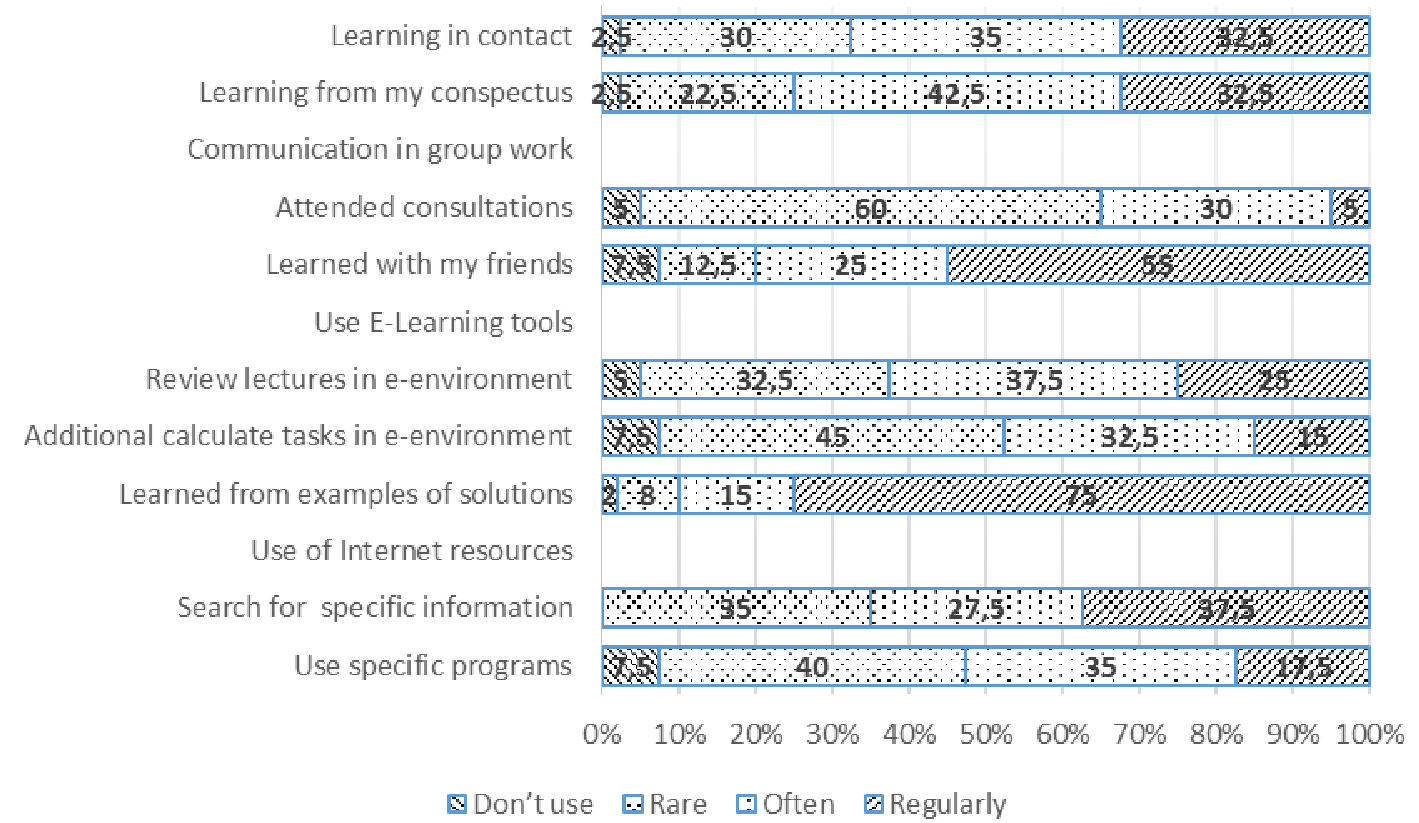

Fig. 3. Learning habits and frequency of mathematics students of the Forest Faculty of LLU

In order to prepare for the test in mathematics, students must be able to calculate the different types of problems that are solved in practical work. In addition, students have to calculate and submit individual homework (tasks are given in the e-environment randomly), as well as students have the opportunity to solve additional tasks indicated in the e-environment. Concerning the use of e-learning materials, more than $75 \%$ of students from both faculties prefer examples of problem solving rather than learning different problem solving methods. This is also evidenced by the fact that the students are reluctant to solve the additional tasks proposed in the e-studies; FTF regularly $-14.3 \%$, often$21.4 \%, \quad($ mode $=$ median $=$ "partly "), FF regularly $-15.0 \%$, often- $32.5 \%$, $($ mode $=$ median $=$ "partly"). About $71.4 \%$ of FTF students $($ regularly $-35.7 \%$, often- $35.7 \%)$ and only $62.5 \%$ of FF students (regularly $-25.0 \%$, often- $35.5 \%$ ) review lectures again in e-studies. 
Analyzing the students' habits of using Internet resources in the learning process it can be concluded that only $65 \%$ (often and regularly) FF students search for specific information on the Internet. The FTF students take this opportunity more seriously - often and regularly $71.7 \%$. As regards the use of specific mathematics programs, as already mentioned, the acquisition of the MatLab program is included in the mathematics study course. However, not all students have access to the MatLab program for solving individual assignments at home, so students can take advantage of online programs. Approximately $78.5 \%$ of FTF students (regularly $-21.8 \%$, often- $42.9 \%$ ) and only $52.5 \%$ of FF students (regularly $-17.5 \%$, often- $35.0 \%$ ) use programs available on the Internet. The most popular mathematics software among the surveyed students are Photomath, Symbolab and Integral Calculator. Unfortunately, many math software not only give results, but also show the solution step by step. Studying mathematics, mathematics programs should serve as a testing tool, not as information how to solve problem, because students often even don't understand what they have solved at homework.

As mentioned above, in the study of mathematics, the emphasis is on solving specific problems. Therefore, self-assessment theory tests have been developed in the e-learning course to help better understand mathematical problems. The mathematics course for FF and FTF students is relatively small, so the theory tests are only suggestive. Research shows that only $11.3 \%$ of students of the FF and $17.2 \%$ of the FTF students were used for these tests. This also correlates with the average results in these faculties. Students of the Faculty of Information Technology (ITF) and the Faculty of Engineering (EF) must obtain at least 4 points (from10) in the theory tests, with no limited number of repetitions.

Figure 4 shows that there is a relationship between students' assessment in the theory test and the final assessment of a mathematics course (for ITF $r=0.98$, for EF $r=0.99$-correlation is high degree).

Given the fact that students can take the theory test an unlimited number of times, it can be concluded that students are not particularly interested in understanding mathematics more than necessary.

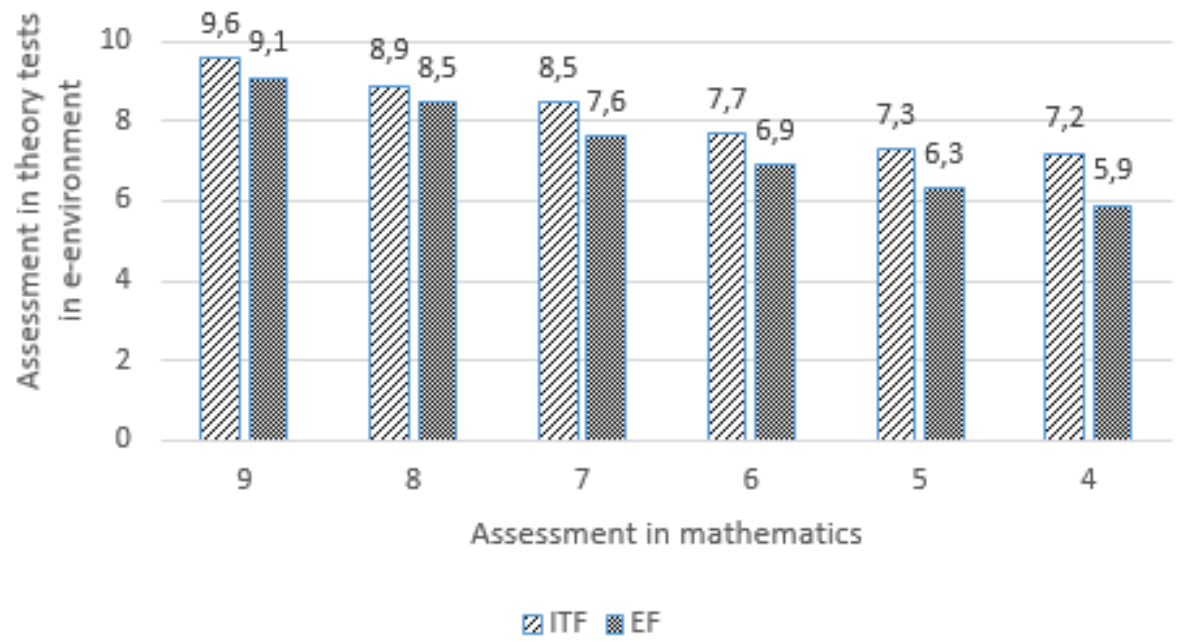

\section{Fig. 4. Relationship between students' performance in mathematics and assessment in theory tests for students of the Faculty of Information Technology (ITF) and the Faculty of Engineering (EF)}

The results of the study show that student performance is less dependent on students' ability to learn mathematics than on laziness and unwillingness to make efforts.

\section{Conclusions}

1. For studying Mathematics in the LLU students use ICT firstly, independently studying e-materials (both informative and interactive), acquiring MATLAB and Excel program for problem solving and in addition, the students can use the Internet resources to find information, use mathematical software, as well as communicate online in chats. Inclusion of ICT in the Mathematics studies 
develops the skills necessary for engineers, such as communication, technical skills and teamwork.

2. Students use ICT mostly for non-academic purposes, mainly for communicating in social networks and entertainment (about $65 \%$ of the time spent on the internet) and only about $35 \%$ of the time spent on the Internet is devoted to academic purposes. It should be noted that the time spent on social networks is significantly higher in the faculties with more females, (in the Faculty of Food Technology more than $30 \%$ ) than in the Faculty of Engineering or Information Technology, where the average time is only $15 \%$.

3. Analysing the students' learning habits in the mathematics course, which offers both contact lessons, e-learning materials (informative and interactive) and the MatLab software, it can be concluded that students with higher basic knowledge of mathematics prefer to study during contact lessons. Regarding recorded lectures in BigBlueButton, students have a positive attitude, although opinions are divided - some students believe that then contact lectures are no longer necessary, others believe that it is a good addition to contact lectures. Concerning the use of elearning materials, more than $75 \%$ of students from both faculties prefer examples of problem solving rather than learning different problem solving methods.

4. As for the students' habits to use the Internet resources in the learning process, it can be concluded that the students with better results in mathematics use them more (FTF - about $71.7 \%$, FF - about $65 \%$ ). Approximately $78.5 \%$ of FTF students and only $52.5 \%$ of FF students use programs available on the Internet. Unfortunately, many math software are step-by-step calculators. Studying mathematics, mathematics programs should serve as a testing tool, not as information how to solve problem, because students often even do not understand what they have solved at homework.

5. Although the emphasis in the mathematics course is on problem solving, understanding theory also plays an important role, as evidenced by the relationship between students' performance in mathematics and assessment in theory tests.

6. Increasing the impact of ICT in the study process, not only many students will have to change their learning style, but also the teaching staff will have to change the study process of their subjects.

\section{References}

[1] Tinne De Laet. Engineering Education Research Engineering Education Research WG @ SEFI 2018 [online] [12.11.2019]. Available at: https://www.sefi.be/activities/special-interestgroups/engineering-education-research/

[2] 10 Essential Skills That Hiring Managers Look For In Engineers. Interesting Engineering. [online] [03.02.2020]. Available at: https://interestingengineering.com/10-essential-skills-thathiring-managers-look-for-in-engineers

[3] Jianzhong C., Koo B. ICTs for new engineering education. Policy Brief. UNESCO Institute for Information Technologies in Education. Periodical issue February, $201112 \mathrm{p}$. [online] [12.11.2019]. Available at: https://unesdoc.unesco.org/ark:/48223/pf0000193683

[4] International Literacy Panel, Educational Testing Service (ETS). (2002). Digital transformation: A framework for ICT literacy. Princeton, NJ: Author. [online] [12.11.2019]. Available at: http://www.ets.org/Media/Tests/Information_and_Communication_Technology_Literacy/ictrepor t.pdf

[5] Rosmah A. et al. Students' ICT conceptions and the challenges in acquiring ICT skills for engineering learning. Proceedings of the Research in Engineering Education Symposium 2013 Kuala Lumpur. [online] [12.12.2019]. Available at: https://www.researchgate.net/figure/Thethematic-map-of-the-challenges-in-acquiring-ICT-skills_fig2_282009985

[6] Williams D et al. Teachers and ICT: current use and future needs. British Journal of Educational Technology, Volume 31, Issue 4, First published: 16 December 2002, [online] [02.02.2020] DOI: /10.1111/1467-8535.00164

[7] Megan K. F, Mendez J., Mobile Learning: How Students Use Mobile Devices to Support Learning. Journal of Literacy and Technology. Vol. 15, No 3, December 2014, pp. 58-78.

[8] Talukder S., Alam J., Apu A.,I., the impact of ICT on students' performance: a case study on undergraduate university students. Manarat International University Studies, Vol.4, No 1, 2015. 
pp. 137-147. [online] [12.11.2019]. Available at: http://miurs.manarat.ac.bd/download/Issue04/15.pdf

[9] A Framework for Mathematics Curricula in Engineering Education. SEFI Mathematics Working Group, 2011. [online] [12.11.2018]. Available at:

http://sefi.htwaalen.de/Curriculum/Competency \%20based \%20curriculum_discussion_document _December_2011.pdf

[10] Booth S. Learning and Teaching for Understanding Mathematics. $12^{\text {th }}$ SEFI Maths Working Group Seminar, Proceedings, Vienna University of Technology, 2004, pp. 12-25.

[11]Zeidmane A. ICT in the Life of Students at the Latvia University of Life Sciences and Technologies. Proceedings of $18^{\text {th }}$ International conference "Engineering for rural development", May 22-24, 2019, Jelgava, Latvia. Vol. 18, pp. 1927-1932. 